\title{
Microbiological Assessment of Bacterial Isolates from Ear, Nose And Throat (ENT) Among Patients Attending Aminu Kano Teaching Hospital
}

\author{
${ }^{* 1}$ M.M Ahmad, 2Z.M. Kurawa, ${ }^{3}$. Shu'aibu, and ${ }^{4}$ G. Yahaya \\ 1 Department of Biology, Kano University of Science and Technology, Wudil, Kano, Nigeria \\ 2Department of Physics, Sa'adatu Rimi College of Education, Kumbotso, Kano, Nigeria \\ 3Department of Microbiology, Gombe State University, Nigeria \\ ${ }^{4}$ Department of Medical laboratory Sciences, Bayero University, Kano, Nigeria
}

[Corresponding E-Mail: mmahmadu@gamil.com, mmahmadu@kustwudil.edu.ng; : : Author: +2348036144784]

ABSTRACT: Samples from patients who reported to in-patient ENT unit of Aminu Kano Teaching Hospital, Kano were isolated for further microbiological assessment. One hundred (100) from both male and female patients comprising 55 ear swabs, 30 and 15 throat and nose swabs respectively were screened between February and April 2014 and the samples were analysed using culture technique, direct microscopy and identification of bacteria (using API 20E strip). Finding from the study identified eight genera of bacteria i.e. Escherichia coli, Haemophilus streptococcus, Klebsiella pneumoniae, Proteus mirabilis, Proteus vulgaris, Pseudomonas aeruginosa, Staphylococcus aureus and Streptococcus pneumoniae. Staphylococcus aureus recorded the highest rates $(24.17 \%)$ which was isolated in ear, nose and throat swabs, while $P$. aeruginosa has $(19.78 \%)$ isolated in only ear swabs. The numbers of microorganisms isolated are as follows: 52 (ear), 14 (nose) and 25 (throat).

Keywords: Prevalence, Bacteria, Ear, Nose and Throat, Isolates

\section{INTRODUCTION}

Ear (Anural), Nose (Nasal), and Throat (ENT) infection are among the most widespread and serious infections that compel an individual to seek medical attention. It represents some of the most common bacterial disease encountered affecting people of all ages. These infections are one of the leading causes of morbidity and mortality in critically ill patients (Witsell et al., 2001). The ear, nose, and throat are the frequent sites of infection, because they come in direct contact with the physical environment and are exposed to air borne microorganisms.

Disease of ear, nose and throat (ENT) affect the functioning of adults as well as children, often with significant impairment of the daily life of affected patients (Witsell et al., 2001). It has been envisaged that with increase in global population, infection remain the most important causes of disease with upper respiratory infections causing hearing loss and learning disability particularly in children (Albert, 1999; Chibuike, et al., 2013; Obiajurn and Chukuezi, 2013). Ear infection such as chronic otitis (tinnitus), have serious consequences in developing countries such as retarded language development and progress in school among children (Newton et al., 2001). Tinnitus which is now known to be the most common childhood infections, lead annually to the death of over 50,000 children under 5 years (Rover et al., 2006) in other cases nasal condition may be distressing, as in the case of nasal myiasis (Kuruvilla et al., 2006).
Bacterial species such as Staphylococcus aureuas, Streptococcus spp, Proteus spp., Haemophilus and Coli forms were found to be responsible for most cases of ENT infections. Elsewhere (Bailey and Scott 1992; Ikeh et al., 1993) implicated Actinomyces israeli, Mycoplasma pneumoniae, mycobacterium tuberculosis and Corynebacterium diptherice as the causes of vary prevalence of ENT infections and disease. Also Kumar et al. (2013) reported that pseudomonas, staphylococcus aureus, proteus and Klebsiella are the common bacteria that cause ENT infection in Japura India. In addition according to a study done on ENT infection in Benin City, Nigeria by Osozuwe et al. (2011) the following bacteria were found in 466 patients enrolled in the study; Pseudomonas aeruginosa, Staphylococcus aureus, Klebsiella spp., Streptococcus pneumoniae, E. coli and Citrobacter frenndi. Based on their study, Pseudomonas aeruginosa was the most prevalent etiologic agent of ENT infections in Benin City. However, according to E-Mahmoud et al. (2010) Streptococcus pyogens, S. pneumoniae, S. aureus, Klebsiella pneumoniae, $H$. influenzae, Proteus mirabilis and $P$. aeruginosa, were the bacteria isolated in the ENT among patients visiting different hospitals in Yola city Nigeria. Based on this study $S$. pneumoniae was the most prevalent bacteria isolated in both ENT infections.

Signs and Symptoms of this infection include, mild to severe pains, fever, and headache (Azeez, 2000), running or stuffy nose, fullness of the ear (Elaine et 
al., 1987) other symptoms and complication include difficulty in swallowing food, meningitis, rhinorrhoea, leryngo stenosis, laryngo paralysis, hearing loss, otitis etc. A number of factors have been implicated by previous workers to cause ENT infections and diseases. These include poor habits of cleanness and hard blowing of the nose as well as excessive sniffing which drives infected mucus into the middle ear leading to otitis media in adults (Schnert, 1996). But Azeez (2000) was of the opinion that otitis is common amongst children due to narrowness of the Eustachian tube, which may fail to drain properly.

The human ear, nose and throat (ENT) are closely related and inter connected parts of the body. Infections, diseases and health problems related to the ENT are therefore jointly studied and managed like the most other part of the human body. The ear, nose and throat were found to be colonized by a wide range of microorganisms some of which are more or less harmless under normal condition (Chibuike et al., 2013).

\section{MATERIALS AND METHODS \\ Selection of Location and Patients}

Aminu Kano Teaching Hospital (AKTH), is known to be a centre for massive influx of patients with one form of complications or another in the whole northwestern region of Nigeria; hence its selection for this research study. One hundred patients who reported to ENT- in- patients unit of this hospital with various signs and symptoms of aural, nasal and throat related infections and diseases were selected randomly for this work. Patient's biodata was as well collected at the registry section of this unit.

\section{Samples Collection}

The throat swab, nasal (nose) swab, and aural (ear) swab were collected aseptically using sterile Evepon swab sticks and the sample collected were properly labeled with patients number, date and the side (i.e. nose, ear, and throat). The swabs were immediately transported in sterile cotton plugged test tube to the microbiology laboratory for further analysis.

\section{Laboratory Analysis of Samples Collected Microscopy}

Throat, ear and nasal (nose) swab collected from the patients were examined microbiologically for the type and number of bacteria, plus cells and relationship of bacteria to pus cells, using culture technique and direct microscopy as describe by Cruideshark et al. (1985) and Cheesbrough (1998).

\section{Culture technique}

Throat swab were inoculated on chocolate agar plates, were as nasal (nose) and ear swab were inoculated on chocolate and MacConkey agar plates. All the plates were incubated for 24 hours aerobically with the exception of chocolate agar plate that was inculcated in a candle jar. The plates were examined for the growth of bacteria and the pathogenic colonies were identified by conventional methods. Haemolysis was studied on chocolate agar plates. Discrete and pure colonies of bacterial isolates were stored instantly in the refrigerator until they were required for identification tests.

\section{Bacteria Identification Test}

The API (Analytical Profile Index) method was used to identify the different types of bacteria that were isolated in the Ear, Nose and Throat swabs using API 20E strip as stated by Shoeb (2010). Different test panels were prepared in dehydrated forms which were reconstituted upon use by addition of bacteria suspension. After incubation, positive test results were scored as a seven digit number (Profile). The bacterium was then derived from the database with relevant cumulative profile software. API 20E presented herein, is a biochemical panel for identification and differentiation of members of the family Entrobacteriaceae, such as Staphylococci spp., Streptococci spp., etc. The plastic strip holds twenty mini test chambers containing dehydrated media having chemically defined composition, for each test.

\section{Statistical Analysis}

The laboratory samples were statistically analysed for test of significance using chi square (Philips, 1973; Onu and lgwenma, 1998).

\section{RESULT AND DISCUSSION}

A total number of 55 ear swabs, 15 nasal swabs and 30 throat swabs were collected from the patients attending Aminu Kano Teaching Hospital. Out of these, ear swabs were positive in $50(56.17 \%), 13$ $(14.61 \%)$ in nose swabs and $25(28.08 \%)$ in throat swabs.

The ear swabs was positive in $26(29.21 \%)$ male and $24(26.96 \%)$ in female, throat swabs was positive in $13(14.60 \%)$ in male $12(13.48 \%)$ in female, while in nose swabs $6(6.74 \%)$ was positive in male and 8 $(8.98 \%)$ in female (Table 1). The findings in this study show that eight genera of bacteria which are $E$. coli, H. strep, K. pneumoniae, $P$. mirabilis, $P$. vulgaris, $P$. aeruginosa, $S$. aureus and $S$. pneumoniae where involved in various ear, nose and throat amongst 
patients examined at the study area. Out of all the organisms isolated $49(53.84 \%)$ occurred in ear swabs followed by throat $26(28.57 \%)$ while the least is $14(15.38 \%)$ in the nose.

Generally, the most prevalent organisms was $S$. aureus $(24.17 \%)$ while the least were $H$. strep, $K$. pneumoniae, and $P$. vulgaris with (4.39\%). S. aureus and $S$. pneumoniae were isolated in both ear, nose and throat swabs, $E$. coli were isolated in ear and nose swabs, $H$. strep., in nose and throat swabs, $K$. pneumoniae and $P$. vulgarias both were isolated in ear and throat swabs, while $P$. aeruginosa was isolated from only ear swabs (Table 2).

Obiajurn and Chukuezi (2013) reported that bacteria spp. S. aureus, S. pneumoniae, Proteus spp. Haemophilus spp. where responsible for most cases of ENT infections, Whereas Rakesh Kumar et al. (2013) find out that Pseudomonas spp., S. aureus, Proteus spp. and Klebsiella spp., are the common bacteria that cause ENT infection in Japura India, similarly Osazuwa et al. (2011) find out that $P$. aeruginosa, S. aureus, Klebsiella spp,. S. pneumoniae, $E$. coli are the bacteria associated with ENT infection and Pseudomonas aeruginosa was the most prevalent aetoliogic agent of ENT infection in Benin city, El-Mohmood et al. (2010) reported that $S$. pneumoniae, $S$. aureus, $K$. pneumoniae, $H$. strep., $P$. mirabilis and $P$. aeruginosa were the bacteria isolated in ENT infection in Yola city. Based on their study S. pneumoniae was the most prevalent bacteria isolated in both ENT infections. These study collaborate the above findings $E$. coli, Haemophilus streptococcus, Klebsiella pneumoniae, $P$. mirabilis, $P$. vulgaris, $P$. aeruginosa, S. pneumoniae and St. aureus were found in both Ear, Nose and throat infection.

But contrary to El-Mohmood et al. (2010) S. aureus was the most prevalent bacteria isolated in ENT infection. While the finding in these research that $P$. aeruginosa was found in only Ear infection collaborate the finding of Osazuwa et al. (2011) that $P$. aeruginosa was the most aetiologic agent of ENT infection in Benin City.

Table 1: Sex Wise Distribution and Culture Result of Patients in Kano, Nigeria

\begin{tabular}{llccc}
\hline Sample & Sex & +ve & -ve & Total examined \\
\hline Ear Swabs & Male & 26 & 3 & 28 \\
& Female & 24 & 2 & 27 \\
Nose Swabs & Male & 6 & 1 & 7 \\
\multirow{2}{*}{ Throat Swabs } & Female & 8 & - & 8 \\
& Male & 13 & 4 & 17 \\
& Female & 12 & 1 & 13 \\
\hline
\end{tabular}

Table 2: Bacteria Associated with ENT Infection in Kano, Nigeria

\begin{tabular}{llllll}
\hline ISOLATES & Ear & Nose & Throat & Total & $\%$ \\
\hline Escherichia coli & 6 & 4 & - & 10 & 10.98 \\
Haemophilus strep. & - & 2 & 2 & 4 & 4.39 \\
Klebsiella pneumoniae & 2 & - & 2 & 4 & 4.39 \\
Proteus mirabilis & 4 & - & - & 4 & 4.39 \\
Proteus vulgaris & 9 & - & 1 & 10 & 10.98 \\
Pseudomonas aeruginosa & 18 & - & - & 18 & 19.98 \\
Staphylococcus aureus & 8 & 8 & 6 & 22 & 24.17 \\
Streptococcus pneumoniae & 2 & 2 & 15 & 19 & 20.87 \\
\hline
\end{tabular}

The age related prevalence of the E.N.T infection in the study area showed that the highest prevalence of the bacterial infection $(47.25 \%)$ is amongst those aged 1 - 10 years, (18.68\%) was amongst the aged greater than 50 years, $(9.89 \%)$ was amongst the aged $11-20$ years $(6.59 \%)$ was amongst neonate (i.e. less than 1 year) and $21-30$ years while the least $(5.49 \%)$ was amongst $31-40$ years and 41 50 years. Miorangthem and Angon (2012) find that the bacteria species isolated from ENT infection in
Sikkim population in India children are $S$. aureus, $P$. aeruginosa and $S$. Pyogens, while in adult $S$. aureus, S. pneumoniae, Klebsiella spp. and E. coli were isolated (Table 3).

Contrary to the above finding the age related prevalence of infection in this study showed that is no any significant difference in the prevalence of the bacteria isolated in different age group $\left(X^{2}=1.0689\right.$, $p=1.064$ ). 
Table 3: Age Related Prevalence of Bacterial Isolates in ENT Infection

\begin{tabular}{lccccccc}
\hline & \multicolumn{7}{c}{ Age } \\
\cline { 2 - 8 } & $<1$ & $1-10$ & $11-20$ & $21-30$ & $31-40$ & $41-50$ & $>50$ \\
\hline E. coli & - & 4 & - & 2 & 1 & - & 3 \\
Haemophilus streptococci & - & 1 & - & - & 2 & 1 & - \\
Klebsiella pneumoniae & - & 3 & - & - & - & 1 & - \\
Proteus mirabilis & 1 & 2 & 2 & - & - & - & - \\
Proteus vulgaris & 2 & 6 & - & - & - & - & 2 \\
P. aeruginos & 3 & 8 & 2 & - & - & 1 & 4 \\
Staphy. aureus & - & 8 & 3 & 3 & 1 & 1 & 6 \\
Strep. pneumoniae & - & 11 & 2 & 1 & 1 & 1 & 2 \\
total & 6 & 43 & 9 & 6 & 5 & 5 & 17 \\
$\%$ & 6.59 & 47.25 & 9.89 & 6.59 & 5.49 & 5.49 & 18.68 \\
\hline
\end{tabular}

\section{REFERENCES}

Albert, P.W. (1999). Pediatric ear, nose and throat service demands and resources: a global perspective. International joJurnal of Pediatrics Otolaryngology, 18(3): 136-139.

Azeez, M.M. (2000). Bacteriology of Otitis Media in Oyo Nigeria. Journal of Medical Laboratory Science, 11(1): 34-39.

Bailey, W.R. and Scott, E.G. (1992). Diagnostic Microbiology $7^{\text {th }}$ edition CV Mosby co. St. Louis pp $88-175$

Cheesbrough, M., (1998). Medical Laboratory Manual for Tropical Countries, University Press, Cambridge.

Chibuike, I., Reginald, A.O., Solomon, U.C., Ifeanyi A.O., Conrad J., Chinenyenwa, J.N., Nnadozie J. and kelechi U.O. (2013). Prevalence and Antibiotic Susceptibility Patterns of MethicillinResistant Staphylococcus Aureus (MRSA) Isolated from Healthy Inhabitants of Uturu Rural Communities, Abia State, Nigeria. Journal of Natural Science Research, 3(10): 85-91.

Cruickshank, R., Duguid, J.P., Marmon, S.P. and Swani, K.H.A. (1985). Medical Microbiology $12^{\text {th }}$ edition. Churchill - living stone.

El-Mahmoud, A.M., A.T., Tirmidhi A.B., and Muhammad, A. (2010). Antimicrobial Susceptibility of some respiratory tract pathogens to commonly used antibiotic at the specialist Hospital, Yola Adamawa State, Nigeria. Journal of Clinical Medicine and Research, 2(8): 135 - 142.

Elaine, P.P., Michael, A.N. and Anne, L.B. (1987). Predictors of Phonologic Inadequacy in Young Children Prone to Otitis Media. The Journal of Speech and Hearing Disorders, 52: 232-242.

Ikeh E.A., Adebayo, E.O., Okuonghae, H.O. and Ighogboja, L.S. (1993). Bacteriology of chronic discharging ears in children in Jos, Nigeria. Journal of Medical Laboratory Science; 3: 27 - 30.

Kumar, R.P., Sriyasteva, M. Sharma, S. Rishi, P.S. and Nwawan, P. (2013). Isolation and Antimicrobial Sensitivity profile of Bacterial Agents in Chronic Supportive Otitis media in patients at NIMS
Hospital, Jaipur. Journal of Research in Nursing and Midwifery, 2(5): 265 - 269.

Kurvilla, G., Albert, R.RA., Anand, J., Ranjith, V.T. and kumar, S.P. (2006). Pneumocephalus a rare complication of nasal myiasis. American Journal of Otolaryngology, 27(2): $133-135$.

Mairangthem, A. and Angom, L.L., (2012). Spectrum of beta haemolytic infections in ENT patients. Journal of Medical Science and Technology, 1(3): $16-23$.

Newton, E.V., Macharia, J., Muswe, P., Ototo, B. and Kan, S.W. (2001). The use of a questionnaire to detect hearing loss in Kenyan pre-school children. International Journal of Pediatric Otolaryngology, 18(3): $229-234$.

Obiajurn, I.O.C. and Chukuezi, A.B. (2013). Microbiological assessment of ENT Infections and disease: Case study at Orlu, Imo state, Nigeria Journal of Research in Nursing and Midwifery, 2(5): $72-76$.

Onuh, M.O. and Igwemma, A.A. (1998). Applied Statistical Techniques First edition CRC Publications Owerri.; pp. 48

Osazuwa, F., Nwofor, Q. and Ibeh, I.N. (2011). Aetiologic Agents of Otitis Media in Benin City, Nigeria. Research Journal of Medical Sciences, 5(2): $112-115$.

Philips, L.O. (1973). Bayesian Statistics for Social Scientists. Whitefriar Press, London, pp. $198-215$.

Rover, M.M, Dekok, I.M.C.M. and Schilder, A.G.M. (2006). Risk factors for Otitis media: An International perspective. International Journal of Pediatric Otolaryngology, 2(1): 1251 - 1256.

Shoeb, Y. (2010). Identification system for Enterobacteriaceae and other non-fastidious Gramnegative rods; API 20E. REF 20100 / 20160.

Schnert, K.W. (1996). How to be your own doctor sometimes. Grosset and Fulap Publishers, New York; pp $20-21$.

Witsell, D.L., Dolor, R.J., Boile, J.N. and Stinnet, S.S. (2001). Exploring health related quality of life in patients with diseases of the ear, nose and throat; A multicenter observation study. Otolaryngology Head and Neck Survey, 125(4): 288-298. 